\title{
Exploring student learning profiles in algebra-based studio physics: a person- centered approach
}

\author{
Jarrad W.T. Pond and Jacquelyn J. Chini \\ University of Central Florida, Department of Physics, \\ 4000 Central Florida Boulevard, Orlando, FL 32816
}

\begin{abstract}
As part of a project to explore successful strategies for using studio methods, such as SCALE-UP, we explore strategic self-regulatory and motivational characteristics of students in said courses at three universities with varying student populations and differing success in studio-mode courses. We survey students using compiled questions from several existing questionnaires designed to measure student characteristics such as attitudes toward and motivations for learning physics, organization of scientific knowledge, experiences outside the classroom, and demographics. Other studies have identified five distinct learning profiles across varying student populations. Using a person-centered approach, we utilize cluster analysis methods to group students into learning profiles to better understand the study strategies and motives of algebra-based studio physics students. We present results from firstsemester and second-semester studio-mode introductory physics courses across three universities. We identify these five distinct learning profiles, found in previous studies, to be present within our student population.
\end{abstract}

PACS: 01.40.-d, 01.40.Fk, 01.40.Di

\section{INTRODUCTION}

Despite their growing popularity, studio-mode introductory physics courses, which support an interactive student-centered learning environment, have seen variable success - as measured by concept inventory performance across institutions [1], [2] and course type (algebra- or calculus-based). As part of a larger project to model success in studio-mode introductory physics courses, this work focuses on student strategic self-regulation and motivational characteristics in studio courses at three large research universities: the University of Central Florida (UCF), Georgia State University (GSU), and George Washington University (GWU). Across these universities, we have identified variable student success in the algebra-based, studio-mode mechanics courses, with the average Force Concept Inventory [3] normalized gains ranging from 0.23 to 0.44 . We are interested in how student study strategies and motivations may play a role in explaining these differences in student success. In previous studies outside of physics education research, five distinct learning profiles have been identified among several student populations [4]. We investigate the presence of these five previously identified learning profiles among students enrolled in our algebra-based introductory studio-mode physics courses. In order to do this, we compile a student characteristic survey from several published and validated questionnaires, similar to those used in Ref. 4, which probes students' strategic self-regulation and motivational characteristics. We establish our survey's reliability and construct validity in our sample. We then use cluster analysis to explore the existence of these five learning profiles among our students. This cluster analysis is "person-centered" in that it uses students' individual responses to find common, coherent groups among the students [4].

We start by discussing the five learning profiles found in previous studies, move to our survey construction and validation, and finish with our cluster analysis and learning profile results and their interpretation in relation to those found in the literature.

\section{FIVE-PROFILE FRAMEWORK}

Shell and Husman initially identified five student learning profiles among undergraduate educational psychology students in a study using canonical correlation to analyze a wide range of motivational, affective, and strategic self-regulatory measures [5]. Information about what motivates and drives a student in a class (motivational), how a student feels in the classroom (affective), and what study strategies and meta-cognitive skills a student uses (strategic self-regulation) work together to define the five learning profiles. These five profiles, or some subset, have been found in several studies using different types of analyses on varying student populations, including middle school earth and space science students, high school biology and chemistry students, and undergraduate introductory psychology and computer science students (see Ref. 4 for a review). The five profiles are: (1) a strategic (Strat) profile of a student motivated to learn and retain the subject material, using whatever self-regulatory strategies are needed to do so; (2) a knowledge-building (KB) profile of a student intrinsically motivated to learn and understand the subject material, but less actively engaged with the course; (3) a surface (Sur) learning profile of a student primarily concerned with passing the course with little engagement in the subject material; (4) an apathetic (Apa) profile of an unmotivated 
TABLE 1. Breakdown of student survey by questionnaire name and scales (variables) measured. Each scale's ordinal $\alpha$ coefficient is given in parentheses to the right of its description.

\begin{tabular}{|c|c|c|}
\hline \multicolumn{3}{|c|}{ Student Perception of Classroom Knowledge-building (SPOCK) - Strategic Self-regulatory Measure [6] } \\
\hline \multirow{5}{*}{$\begin{array}{l}\text { Scales in } \\
\text { SPOCK }\end{array}$} & Self-Regulation [6 items]: & Goal setting, study planning, self-checking understanding $(0.89)$ \\
\hline & Knowledge-building [6 items]: & Synthesis of info gained in course with previous knowledge $(0.90)$ \\
\hline & Low-level Question Asking [4 items]: & Inquiry to bolster test performance, external evaluation $(0.90)$ \\
\hline & High-level Question Asking [3 items]: & Inquiry to satisfy personal curiosity and improve understanding $(0.83)$ \\
\hline & Collaborative Learning [5 items]: & Level of group participation in learning, assignment completion $(0.91)$ \\
\hline \multicolumn{3}{|c|}{ Approaches and Study Skills Inventory for Students (ASSIST) - Strategic Self-regulatory Measure [7] } \\
\hline \multirow{3}{*}{$\begin{array}{l}\text { Scales in } \\
\text { ASSIST }\end{array}$} & Deep Approach [6 items]: & Critical thinking about course material and knowledge synthesis $(0.70)$ \\
\hline & Strategic Approach [6 items]: & Alignment of study behavior with an engaged learner (0.86) \\
\hline & Surface Approach [6 items]: & Lack of managing subject material, hindering learning $(0.86)$ \\
\hline \multicolumn{3}{|c|}{ Class Goal Orientation (CGO) - Motivational Measure [5] } \\
\hline \multirow{3}{*}{ Scales in CGO } & Learning Approach [5 items]: & Importance of understanding, satisfaction with course material $(0.84)$ \\
\hline & Performance Approach [5 items]: & Importance of performing well in relation to other students $(0.77)$ \\
\hline & Task/Work Avoid [3 items]: & Importance of passing the class with as little work as possible $(0.81)$ \\
\hline \multicolumn{3}{|c|}{ Perceptions of Instrumentality (PI) - Motivational Measure [8] } \\
\hline \multirow{2}{*}{ Scales in PI } & Endogenous Instrumentality [3 items]: & Perception of importance of physics knowledge to futu \\
\hline & Exogenous Instrumentality [3 items]: & Perception of importance of physics grade to future success $(0.72)$ \\
\hline \multicolumn{3}{|c|}{ Zimbardo Time Perspective Inventory (TP) - Motivational Measure [9] } \\
\hline Scales in TP & Future [5 items]: & Measure of valuing future reward over immediate sc \\
\hline \multicolumn{3}{|c|}{ Epistemological Beliefs Assessment for Physical Science (EBAPS) - Epistemological Measure [10] } \\
\hline $\begin{array}{l}\text { Scales in } \\
\text { EBAPS }\end{array}$ & $\begin{array}{r}\text { Structure of Scientific Knowledge } \\
\text { [5 items]: }\end{array}$ & View of physics knowledge as disjointed facts or coherent whole $(0.85)$ \\
\hline
\end{tabular}

student that, though wanting to pass the class, invests minimal engagement and personal interest in learning the subject material; and (5) a learned helpless ( $\mathrm{LH})$ profile of a student motivated to pass the course, but unable to optimize self-regulatory study strategies [4].

\section{METHODS AND ANALYSIS}

We compiled a survey of student characteristics, selecting items from different published and validated questionnaires aimed at measuring students' approaches to and self-regulation of learning, their motivations to learn, and their experiences outside the classroom. Table 1 gives a brief outline of the compiled survey items and the student characteristic variables measured. The majority of the questionnaires used to construct our survey were adopted from Ref. 4; however, when certain items from that study were not readily available in the literature, other comparable ones were used in order to probe similar student characteristic variables. These items are those of the Approaches and Study Skills Inventory for Students and the Zimbardo Time Perspective Inventory. Also, two survey scales not used in Ref. 4, the Collaborative Learning scale and the Structure of Science Knowledge scale, were added due to our research interests into group dynamics and epistemologies adopted in the studio-mode courses at the three institutions. All questionnaire items were on a fivepoint Likert scale. We also asked students to report the average number of hours spent studying per week for their physics course (from $1=$ " $<5$ hours per week" to $7=$ " $>30$ hours per week") and how much effort they put into the course compared to their classmates (from $1=$ much less effort to $5=$ much more effort) [4]. A student's scale score is computed by taking the average of the item responses in each scale. The survey was distributed online, and most students were offered a small amount of extra credit for their participation.

Survey results were collected from SCALE-UP-style [2] studio-mode courses at each university. Table 2 gives a breakdown by institution of the number of course sections reporting data and the number of survey respondents. Only those completing the survey, correctly answering two attention-check questions (one near the start and one near the end of the survey), and consenting to research participation are considered.

We evaluated survey reliability by calculating the ordinal $\alpha$ coefficients for each scale [11]. Ordinal $\alpha$ reliability coefficients are calculated using the polychoric correlation matrix, which better estimates the relationships between ordinal items, as opposed to the Chronbach's $\alpha$ that is calculated using the Pearson correlation matrix, and can underestimate the relationship between non-continuous variables [11]. Table 1 gives each scale's ordinal $\alpha$ coefficient. All are above 0.70, indicating sufficient reliability, and most are above or close to 0.80 , indicating high reliability.

To evaluate whether the compilation of different surveys behaves as expected for our population, we employ Confirmatory Factor Analysis (CFA) using the lavaan

TABLE 2. Respondent breakdown by institution.

\begin{tabular}{c|c|c|c}
\hline & UCF & GSU & GWU \\
\hline \# of Sections & 3 & 4 & 2 \\
\hline Survey & 215 & 119 & 123 \\
\hline
\end{tabular}


package in $\mathrm{R}$ [12]. We propose a model with the 15 scales (or latent constructs) listed in Table 1, where each survey item is associated with only the scale that it is proposed to, and we allow the 15 scales to correlate with one another, as one may expect a student's latent classroom strategy and motivational constructs to influence one another. We then use CFA to evaluate if our data supports this model. Following the fit indices presentation guidelines of $\mathrm{Hu}$ and Bentler, we report our standardized root mean square residual (SRMR) and root mean square error of approximation (RMSEA), in addition to $\chi^{2}$ and its associated $\quad p$-value: $\quad \chi^{2}(d f=2323)=4716.844, p<$ 0.001 ; $\mathrm{SRMR}=0.064$; $\mathrm{RMSEA}=0.047$ [13]. We choose to report the RMSEA as it is more appropriate in confirmatory contexts [14]. The combination of a SRMR < 0.09 and a RMSEA $<0.06$ indicates that the proposed model is explained by the data sufficiently and is not overly

TABLE 3. Survey scale score rankings by learning profile. Profile size given in parentheses under profile name

\begin{tabular}{|c|c|c|c|c|c|}
\hline & $\begin{array}{l}\text { Strat } \\
(99)\end{array}$ & $\begin{array}{c}\mathrm{KB} \\
(107) \\
\end{array}$ & $\begin{array}{l}\text { Apa } \\
(43)\end{array}$ & $\begin{array}{c}\text { Sur } \\
(118)\end{array}$ & $\begin{array}{c}\text { LH } \\
(90) \\
\end{array}$ \\
\hline \multicolumn{6}{|c|}{ Strategic Self-regulatory Measures } \\
\hline Self-Regulation & High & Mod. & Low & Mod. & High \\
\hline $\begin{array}{l}\text { Knowledge- } \\
\text { building }\end{array}$ & High & Mod. & Low & Low & Mod. \\
\hline $\begin{array}{l}\text { Low-level } \\
\text { Question Asking }\end{array}$ & High & Mod. & Low & Low & Mod. \\
\hline $\begin{array}{l}\text { High-level } \\
\text { Question Asking }\end{array}$ & High & Mod. & Low & Low & Mod. \\
\hline $\begin{array}{l}\text { Collaborative } \\
\text { Learning }\end{array}$ & High & High & Mod. & Mod. & High \\
\hline $\begin{array}{l}\text { Deep } \\
\text { Approach }\end{array}$ & High & Mod. & Low & Mod. & Mod. \\
\hline $\begin{array}{l}\text { Strategic } \\
\text { Approach }\end{array}$ & High & Mod. & Low & Mod. & Mod. \\
\hline $\begin{array}{l}\text { Surface } \\
\text { Approach }\end{array}$ & Low & Low & Mod. & Mod. & Mod. \\
\hline \multicolumn{6}{|c|}{ Motivational Measures } \\
\hline $\begin{array}{l}\text { Learning } \\
\text { Approach }\end{array}$ & High & Mod. & Low & Mod. & Mod. \\
\hline $\begin{array}{l}\text { Performance } \\
\text { Approach }\end{array}$ & Mod. & Mod. & Low & Low & Mod \\
\hline $\begin{array}{l}\text { Task/Work } \\
\text { Avoid }\end{array}$ & Low & Mod. & High & Mod. & Mod. \\
\hline $\begin{array}{l}\text { Endogenous } \\
\text { Instrumentality }\end{array}$ & High & High & Low & Mod. & Mod. \\
\hline $\begin{array}{l}\text { Exogenous } \\
\text { Instrumentality }\end{array}$ & High & High & Mod. & Mod. & Mod. \\
\hline Future & High & Mod. & Low. & Mod. & Mod. \\
\hline \multicolumn{6}{|c|}{ Epistemological Measure } \\
\hline $\begin{array}{l}\text { Structure of } \\
\text { Scientific } \\
\text { Knowledge }\end{array}$ & High & High & Mod. & Mod. & Low \\
\hline \multicolumn{6}{|c|}{ Study Time and Effort Measures } \\
\hline Study Time & High & Mod. & Low & Mod. & High \\
\hline Study Effort & High & Mod. & Low & Mod. & High \\
\hline
\end{tabular}

complex [13]. The results suggest that the ideal model is supported by the data, and we may use these surveys together as one with confidence.

To investigate the presence of the learning profiles, we utilize the TwoStep clustering method, provided by SPSS V.22 [15], [16]. We use students' scale scores as inputs and log-likelihood as the measure of cluster distance. When a desired number of clusters is specified, an agglomerative hierarchal clustering method [17] is used to cluster the students into groups. Otherwise, the Bayesian Information Criterion (BIC) is used to determine the optimal cluster number given the input data. In the following section, we compare the clustering results using both methods and explore the five-profile solution.

\section{CLUSTERING RESULTS}

The initial cluster analysis with BIC identified two clusters, with one cluster characterized by higher median task/work avoid and surface approach scores and lower scores in the other strategic self-regulatory and motivational scales. We identify this cluster as the unengaged-surface (US) profile and the other cluster as the engaged-mastery (EM) profile. Adopting the five-profile framework, we wish to investigate if the five learning profiles found in previous studies exist in our population. When five clusters are specified in the analysis, we do identify these five learning profiles [4]. Within each survey scale, mean scale scores (and their 95\% confidence intervals) for each of the five learning profiles were inspected in order to rank the profiles relative to each other. Table 3 gives these ranking results.

The five distinct learning profiles identified in our sample of students are consistent with those of Ref. 4 . We see a group of Strat students with relatively high strategic self-regulatory, motivation, and epistemology scores, and high study time and effort levels. $K B$ students share similar motivational and epistemology scores as Strat students, but differ in strategic self-regulation scores. Their knowledgebuilding scores are still considerable, but $K B$ students have lower self-regulation, study less with less effort, and ask fewer questions. They are motivated students, but do not plan and regulate their studies as frequently or seek as much external help compared to Strat students. Apa students have some of the lowest strategic self-regulatory and motivation scores of all the profiles: they study the least, put in little effort, and avoid doing work. Though displaying similar low engagement with the course (i.e., low question asking, moderate study time, and moderate study effort) to that of Apa students, Sur students report moderate levels of selfregulation and relatively higher levels of instrumentality and study time and effort compared to Apa students. Hence, Sur students are slightly more invested in the course, but still desire to do relatively little work. $L H$ students, though scoring low on motivational measures, attempt to regulate their learning and are engaged with the course, but they do so with a relatively high surface approach and low 
epistemology scores. Thus, $L H$ students attempt to regulate their learning, but do so inefficiently. These study behaviors conflict, requiring $L H$ students to put in a lot of time and effort to pass the course.

Ref. 4 studies introductory computer science students and finds the same Strat and $K B$ profiles as found in this study: two profiles that share similar, desirable scores on motivational measures, but differ in their level of selfregulation and engagement. Ref. 4 likewise finds Apa and Sur profiles to share some motivational characteristics, while the Sur students display relatively higher levels of self-regulation and engagement, motivated by higher levels of exogenous instrumentality and performance goals, indicating these Sur students are driven by a desire for higher grades. We see similar Apa and Sur profiles, but with the Sur students instead motivated by higher levels of endogenous instrumentality and future time perspective, indicating our Sur students are finding something intrinsically valuable in the class but still put in little effort. Ref. 4 finds the same $L H$ profile found in this study: a student lacking regulation whose efforts to be strategically self-regulated are not successful.

We now compare the two- and five-cluster solutions displayed in Table 4 to check that the data-driven BIC method of cluster determination is consistent with that of our theoretically-driven five profile solution and to investigate the balance between simplicity and meaning between the two solutions. We find the mapping of two to five clusters to be conceptually consistent: the original engaged-mastery (EM) profile contains all of the Strat students, the majority of the $K B$ students, and the majority of the $L H$ students (who are engaged, but not efficiently). The original unengaged-surface (US) profile contains all of the Apa students and the majority of the Sur students. One surprising result from this comparison is $L H$ students' association with the EM profile due to their high levels of self-regulation. In the two-profile solution, students studying effectively in the course are grouped together with those who do not. Hence, though this solution is simpler,

[1] K. Cummings, J. Marx, R. Thornton and D. Kuhl, Am. J. Phys. 67 (S1), S38-S44 (1999).

[2] R. Beichner, in Research-Based Reform of University Physics (2007), Vol. 1.

[3] D. Hestenes, M. Wells and G. Swackhamer, Phys. Teach. 30 (3), 141-158 (1992).

[4] D. F. Shell and L.-K. Soh, J. Sci. Educ. and Technol. 22 (6), 899-913 (2013).

[5] D. F. Shell and J. Husman, J. Educ. Psychol. 100 (2), 443-459 (2008).

[6] D. Shell et al., The Learning Technology Center, College of Education, The University of Texas at Austin (1996).

[7] N. Entwistle, T. Hilary and V. McCune, Eur. J. Psychol. Educ. 15 (1), 33-48 (2000).

[8] J. Husman and J. Hilpert, Zeitschrift für Pädagogische Psychologie 21 (3/4), 229-239 (2007).
TABLE 4. Comparison of two- and five- profile solutions.

\begin{tabular}{c|c|c|c|c|c}
\hline & Strat & KB & Apa & Sur & LH \\
\hline EM & 99 & 81 & 0 & 6 & 74 \\
\hline US & 0 & 26 & 43 & 112 & 16 \\
\hline
\end{tabular}

meaning is lost with its use, as we may have different instructional reactions to aid a $L H$ student as compared to a Strat or $K B$ student. Given the alignment of our resulting profiles with that of Ref. 4 and the coherence of our twoand five-profile solutions, we are confident in the identification of the five profiles in our student sample. We also see utility in the five-profile solution, as it provides us a more informative snapshot of students in our classrooms.

\section{IMPLICATIONS AND FUTURE WORK}

We were able to identify the five student learning profiles that have been found among different student populations in several prior studies. In further work, we will investigate the stability of these learning profiles across several semesters. We will also conduct follow-up interviews with survey takers to validate our profile definitions. In addition, the profiles will help inform further quantitative analysis, such as structural equation modeling, investigating the complex interactions of the many measured variables. Overall, this person-centered profile approach helps to characterize our students and gives a basis to investigate what students themselves bring to the classroom. Identifying learning profiles and their adoptions among different types of students give insight into students' classroom motivations and study behaviors and allow us, as educators, to better understand and respond to their needs.

\section{ACKNOWLEDGMENTS}

We would like to acknowledge Joshua Von Korff, Brian Thoms, and Noel Klingler for their valuable help with this work. This work was funded by the National Science Foundation (Grant No. DUE 1347515).

[9] P. G. Zimbardo and J. N. Boyd, J. Pers. Soc. Psychol. 77 (6), 1939-1315 (1999).

[10] A. Elby, J. Frederiksen, C. Schwarz and B. White, Retrieved May 9 (2001).

[11] A. M. Gadermann, M. Guhn, and B. D. Zumbo Practical Assessment, Res. \& Evaluation. 17 (3), 1-13 (2012).

[12] Y. Rossell, J. Stat. Software 48 (2), 1-36 (2012).

[13] L.-t. Hu and P. M. Bentler, Structural Equation Modeling 6 (1), 1-55 (1999).

[14] E. E. Rigdon, Structural Equation Modeling 3 (4), 369-379 (1996).

[15] IBM Corp. Released 2013. IBM SPSS Statistics for Windows, Version 22.0. Armonk, NY: IBM Corp.

[16] T. Chiu et al., in Proceedings of the seventh ACM SIGKDD international conference on knowledge discovery and data mining. (ACM, San Francisco, California, 2001), pp. 263-268.

[17] L. Ding and R. Beichner, Phys. Rev. Spec. Top. - PH 5 (2), 020103 (2009). 